\title{
Serum IL-17 and postmenopausal osteoporosis
}

\section{Tharwa H. AL-Tai*}

Abstract:

\author{
BSc, MSc (Microbiology)
}

Background: Osteoporosis is a bone condition that makes bones thininer and more fragile because of reduced bone density and it puts people at risk of fractures, especially of the hip, spinal vertebrae and wrist.

J Fac Med Baghdad

2015; Vol.57, No.4

Received May. 2015

Accepted Nov. 2015
Objective: This study will highlighted the role of IL-17 in postmenopausal osteoporosis.

Patients and methods: This study applied on 84 includes subjects (42 postmenopausal osteoporosis patient and 42 of healthy control group), conducted from December 2014 to March 2015 to measure the IL-17 serum level by using ELISA kit.

Results: In osteoporotic postmenopausal women the mean of serum IL-17 was $(0.49 \mathrm{pg} / \mathrm{ml})$ and it is significantly higher than that of healthy group $(0.09 \mathrm{pg} / \mathrm{ml})$.

Conclusion: Serum IL-17 was significantly elevated in osteoporotic postmenopausal women when compared to healthy postmenopausal women.

Keywords: Postmenopasual, Osteoporosis, IL-17.

\section{Introduction:}

Osteoporosis is a bone condition that makes bones thinner and more fragile because of reduced bone density, and it puts people at risk of fractures, especially of the hip, spinal vertebrae and wrist $[1,2]$. The most common form of osteoporosis is postmenopausal osteoporosis, its main reason is estrogens deficiency $[3,4]$. In the last years, new evidences of the relationship between immune system and bone have been accounted in humans affected by bone disease, such as osteoporosis and bone metastasis $[5,6,7,8]$. IL-17 is a proinflammatory cytokine secreted by activated T-cells. It's ligands and receptors may play an important role in the homeostasis of tissues in health and disease beyond the immune system $[9,10]$. Now IL-17 consider as a new inducer of bone loss in postmenopausal osteoporosis, and it represents across link between estrogen deprivation and increased immune reactivity [11].

\section{Patients and Methods:}

This study was conducted in the period between December 2014 and March 2015. Forty two patients attend « Medical City, Baghdad Teaching Hospital» as newly diagnosed patients of postmenopausal osteoporosis compared to 42 apparently healthy postmenopausal without osteoporosis.

Blood samples were optained from each individual by venous puncture, then was left to clot at room temperature, centrifuged and serum was collected for the detection of human IL-17 by using enzyme linked immunosorbent assay (ELISA) technique. IL-17 ELISA kit (cusabio biotech co., LTD.) human interleukin 17 (catalog No.CSB-E12819h). P.R. china

Statistical analysis: was perfomed using T-test with significant difference at $(\mathrm{p}<0.05)$.

\footnotetext{
*Dept. of Biology/College of Medicine/University of Baghdad. Email:thrwathrwa@yahoo.com
}

\section{Results:}

Table (1) and figure (1) show the difference of serum IL-17 level in osteoporotic postmenopausal women in comparison to healthy group. It shows that the mean of serum IL-17 was $(0.497 \mathrm{pg} / \mathrm{ml})$ and it is significantly higher than that of healthy group $(0.096 \mathrm{pg} / \mathrm{ml})$.

Table (1): Distribution of the serum IL-17

\begin{tabular}{ccccc}
\hline & Type & N* & Mean \pm SD pg/ml & p.value \\
\hline IL-17 & Patient & 42 & $0.497 \pm 0.456$ & $0.0005[S * *]$ \\
\hline & Control & 42 & $0.096 \pm 0.145$ & \\
\hline
\end{tabular}

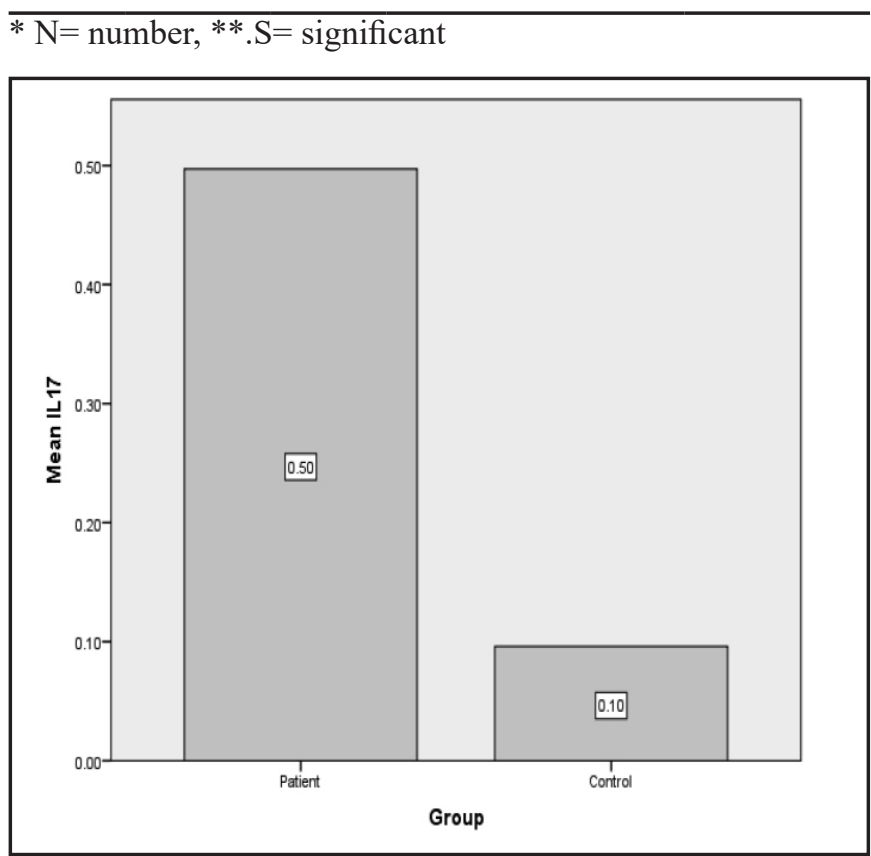

Figure(1):Serum IL-17 level in patients and control 


\section{Discussion:}

As it is known that IL-17 is a cytokine associated with some proinflammatory properties, and it is produced by the T-cell group, known as the Th17 cells $[12,13,14,15]$.Now a day it is known that IL-17 produces not only Th17 lymphocytes but also other types of cells, including macrophages,neutrophils and mast cells[15].In the present study, serum IL-17 were significantly higher in postmenopausal osteoporotic women. This result agreed with other results who showed that IL-17 can play in inducing chronic inflammatory events such as bone loss[16,17,18,19]. Some studies shown that IL-17 localized at the top of the inflammatory cytokine cascade and it stimulates fibroblasts, synoviocytes and macrophages to produce more proinflammatory cytokines[12]. Moreover, an inhibition of IL17 having bone spring effect under overiectamy by antibody approach could form the basis for using humanized antibody against this cytokine towards the treatment of postmenopausal osteoporosis [20]. Thus, results of recent research significantly expanded our ideas in pathogenesis of postmenopausal osteoporosis $[21,22]$.At present,on a cellular and molecular scaie it proved the impotant and the dominant role of immune factors in the development of osteoportic violations of bone tissue is likely to be caused by the estrogens deficiency[21]. At last, it was recently reported that IL-17 is able promote bone loss by stimulating osteoclast formation and inhibiting osteoblast differentiation [23]. Indicating once again the role of the immune system in the regulation of bone turnover $[8,23,24,25]$.Other studies paid attention to the relation between immune system, estrogen deficiency and bone loos ;some of pathways have been clarified where as others remain an unexplained challenge[25].

\section{Conclusions:}

Serum IL-17 was significantly elevated in osteoporotic postmenopausal women when compared to healthy postmenopausal women.

\section{References:}

1- Bethesda and Maryland. Osteoporosis. Us: National Institute of Arthritis and Musculoskeletal and Skin Diseases. 2014; 25: 1-9.

2- Oak B and Illinois. Bone densitometry. US: Radiological Society of North America, RadiologInfo. 2014;25:2.

3- Illovayskaya I.A., Mikhailova D.S., Repina E.A. The effect of estrogen on the functional state of the immune system women. Immunology. 2011; 2-p.109-112.

4- Povoroznyuk V.V., Grigoieva N.V. Menopause and osteoporosis. Reproductive Endocrinology . 2012; 2-p.40-47.

5- Clowes J.A., Riggs B.L and Khosla S. The role of the immune system in the pathophysiology of osteoporosis. Immunological
Reviews.2005; 208: 207-227.

6- Arron J.R and Choi Y. Bone versus immune system. Nature.2000; 408 (6812):535-536.

7- Maria F.F; Annamaria V; Flaviana M. and Luciano C. Postmenopausal osteoporosis the role of immune system cells. Chlinical and Developmental Immunology. 2013; 2013 ( 75936): 6 .

8- Patrizia D. The immune system and Postmenopausal osteorosis. Immunol .Invest. 2013; 42(7): 544-554.

9- Mplnar L; Bohaty L and Somogyine V.E. IL-17 mediated sRANK ligand elevation involved in postmenopausal osteoporosis. Osteoporos. Int. 2014; 25(2): 783-6.

10-Moseley T.A. and Haudenschild D.R., Rose L and Reddi A.H. Interleukin -17 family and $I L-17$ receptors. Cytokin growth factore. Rev. 2003; 14(2):155-74.

11-Dariusz B; SeremakMA; kotrych D; Bogacz A and Kaminski A. Polymorphism of interleukin-17 and its relation to mineral density of bones in perimenopausal women. European Journal of Medical Research.2014; 19: 69.

12-Miossec P. Interleukin-17 in fashion, at last: ten years after its description, its cellular source has been identified. Arthritis Rheum.2007; 56: 2111-2115.

13-Harrington LE., Hatton RD., Mangan PR., Turner H., Murphy TL., Murphy KM. and Weaver CT. Interleukin-17 prodcuing CD4t effector Tcell develop via alineagedistincr from the Thelper type 1 and 2 lineages. Nat. Immunal.2005; 6: 1123-1132.

14-Gillespie M.T. Impact of cytokines and T lymphocytes upon osteoclast differentiation and function .Arthritis Res. Ther.2007;9:103.

15-Paulo G and Maria L .Osteoporosis and inflammation.Arq Bras Endocrinal Metab.2010; 54 (2).

16-Molnar L, et al. High prevalence of increased interleukin$17 \mathrm{~A}$ serum levels in postmenopausal estrogen deficiency. Menopause. 2014; 21(7): 749-752.

17-Bluher $S$ and Mantzoros G.S. Leptin in humans:lessons from translation research.Am.J.Clin.Nutr.2009;89:991-997.

18-Weitzmann M.N and Pacifici R. The role of T lymphocytes in bone metabolism.Immunol.Res.2005;208:154-168.

19-Jaya $G$, et al .Abone-protective role for $\mathrm{IL-17}$ receptor signaling in ovariectomy-induced bone loss .Eur.J.Immunol.2009;39:2831-2839.P

20-Tyagi A.M., Srivastava K., Mansoori M.N., Trived, R. Chattopadhyay $N$ and Singh D. Estrogen deficiency induces the differentiation of IL-17 secreting Th17 cells: anew candidate in the pathogenesis of osteoporosis. PLos one.2012;7(9) 44552.

21-IIoaopozhok B.B., pezhuyehko H.A and Maunrh Z.A. Osteoimmunology: immunologicalmechanisms inpathogenesis of postmenopausal. Reproductive endocrinology. 2013;6 (14). 22-Louis S.T. and Missouri .Estrogen,cytokines and 
pathogenesis of postmenpausal osteoporosis. 1996;11(8):1043-

51.

23-Marjolaine $G$ and Gael Y.R. Inflammation and bone remodeling pathologies. International Journal of or Thopaedics. 2014;1(4).

24-Weitzmann M.N and Pacifici R. Estrogen deficiency and bone loss:an inflammatory tale.Journal of Clinical Investigation. $2006 ; 116(5)$ : 1186-1194

25-Srivastava G., Toraldo M.N., Weitzmann S.,Cenci F., Ross $P$ and Pacifici R.Estorogen decreases osteoclast formation by down-regulation receptor activator (RANK).Journal of Biological Chemistry. 2001;276 (12): 8836-8840. 